\title{
OCUPAÇÕES NO SUL DE MINAS: AUTOGESTÃO, FORMAÇÃO POLÍTICA E DIÁLOGO INTERGERACIONAL'
}

\author{
OCCUPATIONS IN THE SOUTH OF MINAS GERAIS, BRAZIL: \\ SELF-MANAGEMENT, POLICY TRAINNING AND INTERGERACIONAL DIALOGUE
}

\author{
OCUPACIONES EN MINAS GERAIS SÚR, BRASIL: \\ AUTOGESTIÓN, FORMACIÓN POLÍTICA Y DIÁLOGO INTER-GERACIONAL
}

\begin{abstract}
Luís Antonio Groppo ${ }^{1}$ Júnior Trevisan ${ }^{2}$

Lívia Furtado Borges ${ }^{3}$

Andréa Marques Benetti ${ }^{4}$

\section{RESUMO}

Em reação à Medida Provisória que reforma o ensino médio e à Proposta de Emenda Constitucional que congela os gastos sociais do Estado, passaram a ocorrer, a partir de setembro de 2016, em diversos estados do Brasil, ocupações por estudantes de escolas de Ensino Médio e universidades. Ocupações em escolas e em uma universidade do Sul de Minas Gerais foram investigadas por meio de pesquisa de campo pelos autores, com dados interpretados a partir de referencial teórico acerca dos conceitos de autogestão, formação política e diálogo intergeracional, buscando compreender aspectos educativos relevantes desses movimentos juvenis. Os resultados indicam a importância da imersão dos sujeitos investigadores na realidade impactante de um movimento social, o que, com a ajuda do uso rigoroso de um referencial teórico estudado pelo Grupo que realizou esta investigação, traz resultados acerca do vigor formativo das ocupações, os quais podem contribuir com a autorreflexão desse movimento. Entre os resultados, está a capacidade de auto-organização do espaço e das atividades educativas pelos próprios jovens estudantes, bem como a construção de uma formação política baseada na horizontalidade das relações e em profícuo diálogo intergeracional.
\end{abstract}

PALAVRAS-CHAVE: Movimento estudantil. Autogestão. Formação política. Diálogo intergeracional.

\section{ABSTRACT}

In reaction to the Interim Measure to reforming high school, and the Proposed Constitutional Amendment to freezing the State social spending, occupations by students from high schools and universities began to take place in various states of Brazil, from September 2016 . Occupations in schools and a university in the South of Minas Gerais were investigated by the authors in field research, with data interpreted from the theoretical framework about the concepts of self-management, policy formation and intergenerational dialogue, trying to understand relevant educational aspects of these youth movements. The results indicate the importance of immersing in striking reality of a social movement, which, with the help of a strict use of a theoretical framework developed by the Study Group that conducted this research, brings results about the formative force for the young people involved in occupations that can contribute to the self-reflection of this movement. Among the results, the ability to self-organization of space and educational activities by young students as well as the construction of a political formation based on the horizontality of relations and fruitful intergenerational dialogue.

\footnotetext{
${ }^{1}$ Doutor em Ciências Sociais e Mestre em Sociologia - Universidade Estadual de Campinas (UNICAMP). Pesquisador do Conselho Nacional de Desenvolvimento Científico e Tecnológico (CNPq); Professor da Universidade Federal de Alfenas (UNIFAL-MG).Email: luis.groppo@gmail.com

2 Universidade Federal de Alfenas (Unifal-MG). Email: juniortrevisansk8@hotmail.com

3 Universidade Federal de Alfenas (Unifal-MG).Email: liviafurtadob@yahoo.com.br

${ }^{4}$ Universidade Federal de Alfenas (Unifal-MG). Email: deabenetti@hotmail.com
}

\section{(C) ETD-Educação Temática Digital Campinas, SP $\quad$ v.19 $\quad$ n.1 $\quad$ p.141-164 jan./mar. 2017}


KEYWORDS: Student movement. Management Education. Political behaviour. Geration gap.

RESUMEN

En reacción a la Medida Provisional que reforma la escuela secundaria, y la Propuesta de Enmienda Constitucional para congelar el gasto social del Estado, la toma por parte de estudiantes de colegios y universidades comenzaron a tener lugar en varios estados de Brasil, a partir de septiembre del año de 2016 . Las ocupaciones de escuelas y una universidad en el Sur de Minas Gerais fueron alvo de la investigación de campo por los autores, con los datos interpretados desde el marco teórico sobre los conceptos de autogestión, la formación política y el diálogo inter-geracional, tratando de comprender los aspectos educativos pertinentes de éstas movimientos juveniles. Los resultados indican la importancia de la inmersión de los investigadores sujetos en sorprendente realidad de un movimiento social, el cual, con la ayuda de un uso estricto de un marco teórico desarrollado por el grupo de estudio que llevó a cabo esta investigación, aporta resultados sobre la fuerza formativa para el jóvenes que participan en ocupaciones, que pueden contribuir a la autoreflexión de este movimiento. Entre los resultados, la capacidad de auto-organización de los espacios y las actividades educativas de los jóvenes estudiantes, así como la construcción de una formación política basada en la horizontalidad de las relaciones y fructífero diálogo inter-generacional.

PALABRAS CLAVE: Movimiento Estudiantil. Autogestión. Formación política. Brecha generacional.

\section{INTRODUÇÃO}

Em 22 de setembro de 2016, o governo federal decretou a Medida Provisória no 746/2016 (MP746), a qual altera a Lei no 9.394, de 20 de dezembro de 1996, que estabelece as Diretrizes e Bases da Educação Nacional, e a Lei no 11.494 de 20 de junho de 2007, que, por sua vez, regulamenta o Fundo de Manutenção e Desenvolvimento da Educação Básica e de Valorização dos Profissionais da Educação, e dá outras providências. Quase imediatamente, escolas públicas de ensino médio começaram a ser ocupadas no Paraná, especificamente em protesto contra a MP746. Em outubro do mesmo ano, o governo Temer enviou a Proposta de Emenda à Constituição no 241, de 2016 (PEC241) ao Congresso Nacional, a qual altera as Disposições Constitucionais Transitórias, instituindo um novo Regime Fiscal à nação, "congelando", por 20 anos, os gastos públicos com políticas sociais, como a educação, a saúde e a assistência. Aprovada no mesmo mês de outubro em regime de urgência pela Câmara dos Deputados, a PEC foi encaminhada ao Senado e recebeu novo número: PEC55. Em reação, não apenas mais escolas públicas foram ocupadas, em todo o país, mas também campi de universidades federais foram tomados por seus estudantes.

No final de outubro, quando construíamos a proposta deste artigo, o movimento social de ocupações atingira seu auge, com 1.154 escolas segundo a UBES (União Brasileira dos Estudantes Secundaristas) - mais de 800 no Paraná (FOLHA DE S. PAULO, 26/10/2016) - e 123 campi universitários tomados por seus estudantes. (INTERVOZES, 2/nov./2016).

\section{(C) ETD-Educação Temática Digital Campinas, SP $\quad$ v.19 $\quad$ n.1 $\quad$ p.141-164 jan./mar. 2017}


Este artigo trata de uma onda de ocupações de unidades de ensino que, no mínimo, tem se apresentado como um potente, mesmo que fugaz, movimento social de estudantes adolescentes e jovens, apoiado por coletivos juvenis de esquerda ${ }^{5}$ e por parte de adultos que são seus educadores ou responsáveis. Mais do que debater o caráter fugaz ou não desse movimento, este artigo tem o objetivo principal de, "no olho do furacão", a partir da imersão de seus autores no seio de ocupações no Sul de Minas Gerais, compreender alguns dos seus aspectos educativos. Eles estão presentes principalmente na autogestão do espaço ocupado, na formação política construída pela participação direta na ação e nos diálogos intergeracionais conquistados ou ao menos buscados. São esses os principais temas deste texto.

As ocupações observadas no Sul de Minas pelos autores têm envolvido os sujeitos investigados pela pesquisa $A$ dimensão educativa das organizações juvenis: Estudo dos processos educativos não formais e da formação política no interior de organizações juvenis de uma universidade pública do interior de Minas Gerais ${ }^{6}$, que trata dos coletivos estudantis atuantes em uma universidade desta região. Buscamos contribuir com as discussões acerca do caráter educativo dos movimentos sociais e com o estudo dos processos de formação política dos jovens.

As fontes deste texto são relatos registrados em diários de campo pelos autores, matérias sobre as ocupações veiculadas pela imprensa comercial e alternativa e revisão bibliográfica acerca de formação política, autogestão e diálogo intergeracional. Trata-se de um trabalho coletivo de investigação e reflexão, feito, em parte, "no calor da hora", com a intenção de inserir esse movimento nas discussões acadêmicas, captando-o in loco, em tempo real, mas a partir de reflexões teóricas relevantes, no cotejo com teorias e conceitos tratados pela pesquisa "A dimensão educativa das organizações juvenis" - já que os autores fazem parte do Grupo de Estudos sobre a Juventude de Alfenas-MG, da Unifal-MG (Universidade Federal de Alfenas), que têm se reunido para estudar o tema desde o início de 2016. Buscamos construir conhecimentos objetivos que podem colaborar com a autorreflexão dos sujeitos que têm participado do movimento e com o próprio meio acadêmico que pesquisa a educação, trazendo, para mais perto de nós, falas e ações de pessoas que têm exercido algo de heroico, mas tão humano, que é a entrega à solidariedade de um movimento social. (JASPERS, 2016).

\footnotetext{
5 Com base em Norberto Bobbio (2001), define-se esquerda como forças políticas ligadas a partidos, sindicatos e movimentos sociais, entre outros, que tendem a valorizar ações que aumentam ou reforçam a igualdade social.

${ }^{6}$ Pesquisa coordenada pelo Prof. Dr. Luís Antonio Groppo, amparada por Bolsa de Produtividade em Pesquisa do CNPq (Conselho Nacional de Desenvolvimento Científico e Tecnológico) e vinculada ao Grupo de Pesquisa Filosofia, História e Teoria Social e ao projeto de extensão Grupo de Estudos sobre a Juventude de Alfenas-MG da Unifal-MG (Universidade Federal de Alfenas).
}

(C) ETD-Educação Temática Digital Campinas, SP $\quad$ v.19 $\quad$ n.1 $\quad$ p.141-164 jan./mar. 2017 


\section{CENÁRIO}

Em 2016, houve uma nova interrupção da normalidade democrática em nosso país, passados trinta e um anos desde o final da Ditadura Civil-Militar. Diferente do golpe de 1964, que instaurou esse regime ditatorial, não se trata agora de uma interrupção ${ }^{7}$ com base expressiva na força, tendo como principal agente as Forças Armadas, aplicado de modo expresso sob a alcunha de uma "revolução". Em 2016, trata-se da instalação paulatina de um estado de exceção ${ }^{8}$, aparentemente seguindo procedimentos legais, por meio de uma coalizão que atravessa o poder executivo (após a deposição de Dilma Rousseff), o poder legislativo e setores hegemônicos do poder judiciário. Entre os exemplos desse processo, citam-se a articulação de setores da inteligência e das forças policiais para vigiar e reprimir movimentos sociais e importantes decisões, como a MP746 e a PEC55, tomadas à revelia da opinião pública.

Inclusive, graças a diversos espaços democráticos ainda mantidos, houve uma reação mais rápida a esse crescente estado de exceção, em comparação a 1964, mais propriamente contra as medidas de grande impacto tomadas pelo governo sem qualquer preocupação com o diálogo com a sociedade civil, a MP746 e a PEC55. Essa reação veio, primeiramente, de adolescentes estudantes do ensino médio, os quais motivaram, em um segundo momento, ocupações de campi universitários. Esse movimento tem se mostrado mais abrangente e impactante, até o momento, se comparado a outras tentativas feitas por partidos de esquerda, sindicatos e movimentos sociais consolidados para conter a escalada autoritária.

A mobilização juvenil, não deve ser encarada como elemento totalmente novo ou inesperado, tendo em vista as ocupações de escolas públicas perpetradas em estados como São Paulo, Goiás e Rio de Janeiro em 2015 e 2016. (PIOLLI; PEREIRA; MESKO, 2016, ANTUNES, 2016). Contudo, tais ocupações trataram-se de movimentos mais localizados, de caráter estadual, em oposição a medidas tomadas por governos em relação ao seu sistema de ensino médio (em São Paulo, contra o fechamento de escolas, em Goiás, contra a entrega da administração de escolas a organizações sociais) ou em apoio à greve de professores (no Rio de Janeiro). A partir de setembro de 2016, as ocupações das escolas têm efetivado um movimento de caráter mais abrangente, ainda que se concentre em alguns estados (em especial, no Paraná), pois a PEC55 e a MP746 tratam de causas nacionais.

\footnotetext{
${ }^{7}$ A publicação da CLACSO (Consejo Latinoamericano de Ciencias Sociales), editada por Pablo Gentili (2016a), não hesita em chamar o ocorrido de "golpe", ainda que de diferente tipo, um "golpe institucional", baseado em uma "farsa", a saber, o esforço em dar ao golpe ares de legalidade e mesmo de republicanismo, com base no fato de terem sido seguido os ritos procedimentais supostos para um processo de impeachment.

8 Na mesma publicação da CLACSO citada acima, artigos como o de Gentili (2016b) consideram que o estado de exceção vem se costurando por meio da criminalização de movimentos sociais e do uso do poder judiciário de forma seletiva, para retirar do jogo político e eleitoral dadas figuras chave da vida pública.
}

\section{(C) ETD-Educação Temática Digital Campinas, SP $\quad$ v.19 $\quad$ n.1 $\quad$ p.141-164 jan./mar. 2017}


Há outro precedente que é preciso ao menos citar, a saber: as Jornadas de Junho de 2013. Complexas, as Jornadas tiveram ao menos duas dimensões, sendo a primeira a mais relevante de tratar, graças ao legado que deixou às atuais ocupações. A primeira dimensão foi a dos protestos encabeçados pelo Movimento Passe Livre (MPL) contra o aumento das tarifas do transporte público, expressando demandas populares e juvenis pelo acesso aos bens públicos, como o transporte e o direito a usufruir mais plenamente dos equipamentos sociais e de lazer que as cidades oferecem. Contestavam-se também as tendências das políticas sociais dos governos Lula e Dilma, que focaram a ampliação do acesso a bens de consumo privados, mais do que a ampliação dos direitos sociais. (MARICATO et al., 2013).

A segunda dimensão das Jornadas de 2013, que ao menos em parte está na origem das mobilizações favoráveis ao impeachment de Dilma Rousseff, foi a da ampliação do público das manifestações e a dispersão das demandas. As mídias comerciais contribuíram para conformar um suposto discurso geral "antipartidário", nacionalista e anticorrupção. De toda forma, rompiase a coalizão entre forças progressistas e forças conservadoras que sustentara os governos petistas desde 2003. (MARICATO et al., 2013).

Ainda que reconheçamos a necessidade de pensar em conjunto ambas as dimensões das Jornadas de 2013, para assim compreender melhor os sentidos desse movimento (ARANTES, 2014), destacamos aqui a sua primeira dimensão. Essa dimensão contestadora e criativa de Junho de 2013, em parte relevante representada pelo MPL, trazia uma tendência educacional e de formação política retomada pelas recentes ocupações, marcada pela: valorização da horizontalidade da participação, da tomada de decisões e até das análises de conjuntura; concepção ampliada da política e reconhecimento das diversas possibilidades de participação (partidária ou não); e gestação de práticas educativas não formais próprias, inclusive por meio da ressignificação de tradições da educação popular e dos movimentos sociais de outrora. (SOUSA, 214). As discussões mais propriamente conceituais, a seguir, podem contribuir para a compreensão dessa tendência formativa, que também está presente nos movimentos juvenis mais recentes em nosso país.

\section{AUTOGESTÃO, FORMAÇÃO E DIÁLOGO}

Um primeiro elemento de destaque nas ocupações é a capacidade de auto-organização dos estudantes. Inesperadamente, tendo em vista os dados e os inúmeros relatos acerca da crise de sentido do ensino médio, os estudantes passam a considerar o espaço escolar como o seu espaço. Formam comissões e organizam a limpeza, a conservação, a vigilância, as atividades políticas e formativas. Constroem regras e tomam decisões a partir de assembleias soberanas.

(C) ETD- Educação Temática Digital Campinas, SP $\quad$ v.19 $\quad$ n.1 $\quad$ p. 141-164 jan./mar. 2017 
O termo autogestão é um daqueles que tenta referenciar essa capacidade e esse desejo próprio dos humanos, a saber, o de tomar conta de seu destino, em vez de delegar a outrem esse poder. Há outros termos correlatos, como autonomia, auto-organização, democracia direta, participação, democracia participativa. A origem e o desenvolvimento do conceito de autogestão estão muito ligados às experiências cooperativas e anarquistas, desde o século XIX. Nessas, a autogestão significa a submissão das decisões de controle e gestão às necessidades, interesses e desejos dos indivíduos que compõem a unidade social a ser administrada. Envolve a democratização radical não apenas das instituições governamentais, mas sobretudo das atividades do cotidiano, nas esferas socioeconômicas. (FOLLIS, 2000).

As primeiras experiências e sistematizações acerca da autogestão envolveram principalmente as atividades econômicas, com base na formação de cooperativas de consumo e produção ou na tomada do poder decisório em fábricas ocupadas. (SANTOS; RODRIGUEZ, 2002). A tática da ocupação tem, assim, uma ligação histórica com a vontade autogestionária.

Nos anos 1960, sobretudo nos movimentos estudantis de 1968, com destaque à França, a ideia da autogestão foi apropriada pelos estudantes em universidades e escolas ocupadas para se referir à possibilidade de os próprios jovens tornarem-se os gestores de seu processo formativo. A ideia buscava romper tanto com a lógica pedagógica tradicional que opunha "os que sabem" aos "que nada sabem", quanto com a desigualdade ferrenha entre as categorias etárias, em especial entre jovens e adultos. (NATANSON, 1968).

Ainda em meados do século passado, os franceses do movimento da pedagogia institucional, como Lapassade, Lourau e Lobrot, criaram a tese da autogestão pedagógica (VIANA, 2008). O artigo publicado na Revista Vozes, em 1973, incluindo Lapassade entre seus autores, descreve a seguinte tese:

A autogestão pedagógica é um sistema de educação no qual o mestre renuncia a transmitir uma mensagem. Os alunos, em nível de classe ou da escola, dentro dos limites da situação escolar atual, decidem a respeito dos métodos, das atividades escolares e dos programas de formação. Na pedagogia institucional ou autogestão pedagógica, o mestre não é um transmissor de informações, mas analista do processo de aprendizagem ou perito à disposição da classe que deve encontrar e desenvolver suas instituições internas próprias. (Revista Vozes, 1973 apud VIANA, 2008, p. 41).

(C) ETD-Educação Temática Digital Campinas, SP v.19 $\quad$ n.1 $\quad$ p.141-164 jan./mar. 2017 
Como pudemos explorar em outros estudos (GROPPO, 2006), essa tese é uma boa descrição do que foram as práticas de organização dos espaços educacionais ocupados pelos jovens em 1968, bem como das atividades formativas e educativas que fomentaram. A principal diferença em relação à tese é que a autogestão foi possível apenas com uma interrupção no cotidiano, por meio da greve geral e da ocupação das unidades de ensino. São muitos os relatos do intenso aprendizado político e mesmo acadêmico nos ambientes das ocupações, lado a lado com a ideia de que as escolas e universidades pertenciam aos estudantes.

Nos espaços ocupados, os estudantes tendem a realizar outros processos de formação política. Trata-se de uma formação política que rompe com a concepção tradicional, marcada pelo conceito de socialização política. Na concepção tradicional de socialização política, os sujeitos são trazidos à vida política, "socializados" para a esfera da vida pública, por meio de instituições comandadas por adultos, em especial a família e a escola. Tal socialização caracteriza-se pelo aprendizado dos valores vigentes e supostamente necessários para o bom funcionamento das instituições políticas formais dadas, como Estado, partidos, sindicatos, sistema eleitoral etc. (OPPO, 1998).

Nas ocupações, assim como em tantos outros movimentos sociais e culturais protagonizados por adolescentes e jovens na modernidade e contemporaneidade, os sentidos da formação política podem ser outros. Primeiramente, ela pode ser guiada pelos próprios jovens e seus coletivos ou grupos, de modo paralelo às ações de adultos, inclusive de forma completamente alheia a tais ações e até contra elas. Poder-se-ia considerar tal formação como uma verdadeira auto-socialização política, que às vezes assume o caráter de uma coeducação entre gerações, quando adultos e jovens compartilham aprendizados e permitem-se ensinar-eaprender uns com os outros. (PERALVA, 1997, CASTRO, 2009).

Em segundo lugar, em tal formação política, rompem-se as barreiras entre as funções tradicionais dos agentes educacionais (professores versus estudantes), os limites e os papéis das categorias etárias (jovens guiados por adultos) e, enfim, as fronteiras entre o público e o privado. Sobre as duas primeiras rupturas, a discussão acima acerca da autogestão na educação já trouxe diversas considerações. Sobre a terceira ruptura, a respeito dos limites entre o público e o privado, é preciso tratar mais. A formação política autopromovida por jovens rompe com a noção de que os que não são ainda adultos estão imersos apenas em questões privadas, incapazes de tratar com acuidade das questões públicas. Faz isso tanto com a ascensão dos assuntos de interesse dos jovens à esfera dos assuntos públicos, quanto com a intrusão de seus pontos de vista em temas que se considerava para além de sua competência. (CASTRO, 2009; RANCIÉRE, 2014). 
Em terceiro lugar, trata-se de uma formação política que nega a ideia de que é preciso primeiro se "qualificar" ou se "habilitar" com valores e atitudes fundamentais, antes de poder agir politicamente e apresentar-se ao mundo público. Ao contrário, concebe-se que o jovem já é um ser político, capaz de agir publicamente e promover mudanças relevantes na ordem social desde seu ponto de vista a respeito dos assuntos públicos. Enfim, trata-se de uma formação em que a participação de todos os sujeitos é valorizada, tanto pela horizontalidade das relações entre os membros dos coletivos e movimentos, quanto pela livre abertura ao debate e, enfim, pela expectativa de que é possível intervir diretamente na realidade, sem passar necessariamente pelas instituições estatais ou pelos mecanismos de representação. (MÜXEL, 1997, SILVA; CASTRO, 2013).

Tal concepção e prática de formação política é descrita por Castro e Mattos (2009) com base no conceito de subjetivação política, fundamentado em Jacques Ranciére, para quem a subjetivação política consiste "na formação de um eu, não como um si mesmo, mas como uma relação de um si para um outro." (apud CASTRO; MATTOS, 2009, p. 798). Nessa formação, relacional, em que o jovem sujeito depara-se com os adultos, os espaços não convencionais da política têm grande importância. Na verdade, tem-se uma ampliação do que se considera como espaços políticos quando, por exemplo, as ocupações tornam escolas e campi universitários novos cenários políticos. Em segundo lugar, os conflitos e os choques entre as vontades dos sujeitos cumprem importante papel para forjar identificações. Nesse sentido, jovens e adultos são forçados ao diálogo, não mais para que simplesmente aqueles que "tudo sabem" guiem os "que nada sabem", mas para que uns e outros possam tentar superar os conflitos inevitáveis entre suas vontades.

Propostas interessantes acerca dos diálogos intergeracionais partem da ruptura de alguns supostos tradicionais acerca das categorias etárias e do desenvolvimento humano. Segundo Miguel Arroio (2014), há de se superar a concepção propedêutica a respeito da infância, da juventude e da própria Educação Fundamental e Média, concepção em que essas idades e essas educações valeriam apenas como preparação para as idades e etapas seguintes de aprendizado. Em vez de estágios e desenvolvimento linear, melhor seria pensar em idades e ciclos da vida, considerando que cada tempo humano tem suas especificidades e qualidades, que não se resumem apenas à preparação ao tempo subsequente. (MOLL, 2013).

Nessa concepção, a própria idade adulta não é mais pensada como etapa final do desenvolvimento humano, ponto de chegada do aprendizado dos sujeitos. $\mathrm{O}$ adulto não deve ser visto como um ser humano "completo", destoando das supostas incompletudes das demais idades do ciclo da vida. (OLIVEIRA, 2004). É tempo ainda de aprender e se transformar. Os diálogos intergeracionais importam não apenas às crianças e aos jovens, mas também aos adultos e idosos.

(C) ETD- Educação Temática Digital Campinas, SP v.19 $\quad$ n.1 $\quad$ p. 141-164 jan./mar. 2017 
Relativiza-se a exigência típica da modernidade, segundo Walter Benjamin, da "experiência" como requisito à plena participação na vida social e política, maneira de manter o poder dos adultos sobre os jovens e obrigá-los a se adequar à ordem dada. Isso não significa que os jovens não possuíam as suas próprias vivências, ao contrário, mas nessa visão moderna elas foram tratadas oficialmente como inócuas. (SOUSA, 2004). Antes, é preciso que as vivências dos jovens também sejam consideradas como "experiências" relevantes, ainda que constituídas a partir de outras relações com o espaço e o tempo social. Daí a possibilidade dos diálogos entre as gerações e o aprendizado recíproco entre suas experiências, construídas a partir de diferentes modos de estar no mundo e vivenciar o tempo.

Estudos a respeito dos diálogos intergeracionais, em especial na educação, tenderam a focar os idosos, nas suas relações educativas formais e não formais com adultos, jovens e/ou crianças. (PARK; GROPPO, 2009). Menos comuns têm sido as abordagens das relações entre as gerações no interior de um movimento social, pesquisas que tendem a focar as incompreensões e os conflitos entre jovens e adultos, especialmente as imagens arraigadas em lideranças mais velhas a respeito dos jovens, considerados como pouco confiáveis e irresponsáveis. (CASTRO, 2013).

As ocupações das escolas e campi universitários no Brasil em 2016, contra a MP746 e a PEC55, trazem outras perspectivas sobre as relações entre as distintas gerações agrupadas nessas instituições de ensino. Quando estudantes passam a contestar a hierarquia e o controle tradicional desse espaço, via autogestão, quando praticam modos de política e de formação política não institucionais e "não formais" no chão da própria instituição "formal", desafiam seus professores, em geral mais velhos, instam ao choque e conflito tanto quanto ao diálogo e à coeducação.

\section{OCUPAÇÕES NO SUL DE MINAS E FORMAÇÃO POLÍTICA}

\section{Ocupações de escolas no município A}

A Escola Estadual I é uma das mais tradicionais do município A. Tradicional no sentido de ser antiga, a Escola foi Grupo Escolar e a primeira escola pública da cidade a oferecer ensino médio. Tradicional no sentido de ser conservador também, o colégio é tido como uma das "melhores" escolas públicas de ensino médio da cidade e não é raro que mesmo famílias de classe média matriculem seus filhos para estudarem ali, no intuito de terem acesso ao "conteúdo" considerado de qualidade. Esse fator ocasionou resistência muito grande contra a ocupação.

(C) ETD-Educação Temática Digital Campinas, SP v.19 $\quad$ n.1 $\quad$ p.141-164 jan./mar. 2017 
O prédio antigo da escola foi construído para ser sanatório, e foi. As grades do porão ainda guardam as letras que formam a fachada onde se podia ver escrito "Grande Sanatório". Sobre esse ponto, é inevitável a lembrança de Michel Foucault (2004) e sua obra sobre as instituições disciplinares, quartéis, hospitais, sanatórios e escolas, na verdade, todas moldadas sob o mesmo tipo de estrutura, o panóptico, e com formas muito parecidas de controle, em especial o controle dos corpos, ou biopoder. Isso explica como um sanatório tornou-se escola sem a modificação de sua estrutura física básica.

Observa-se um desenvolvimento da contradição, já que o formato da escola, semelhante ao de uma prisão, adotado para garantir as formas constantes de vigilância, é também o que permite sua ocupação atual. Viviane Mosé (2013) afirma que a escola brasileira ainda carrega em si os modelos do reformatório e da prisão. O movimento de ocupação dos estudantes secundaristas ocorre de forma a se utilizar das grades construídas exatamente para aprisioná-los, só que agora como forma de mobilização social, apropriação e reutilização do espaço.

O Grêmio da Escola I surgiu com o movimento dos estudantes em meados do ano de 2015, havendo se consolidado, de fato, no início do ano letivo de 2016. O Grêmio se formou a partir de um projeto impulsionado por estudantes que buscavam negociar a flexibilização da grade curricular do primeiro ano, exigindo mais aulas de Arte e Sociologia. Negociaram com a direção e instituíram a sexta aula, em que ocorreria projeto integrando essas disciplinas. Dessa mobilização, surgiu a iniciativa do Grêmio que, curiosamente, um ano depois, lutaria duramente para que essas mesmas disciplinas não fossem ceifadas do currículo escolar, como se tem interpretado da aplicação da MP746.

O Grêmio, na prática, tem sido liderado por estudantes feministas de diversas turmas dos primeiros anos, que em meados de 2016 formaram um Coletivo feminista. Esse fator tornou-se preponderante nas ocupações do município A. Trata-se de um movimento, sem dúvida alguma, liderado por mulheres. A presidenta do Grêmio, uma adolescente de 16 anos, com suas colegas, articulou uma rede de militância feminista, em consonância com a UBES, e que contou com a participação de diversos outros coletivos.

A ocupação da Escola Estadual I foi o estopim para outras oito ocupações na cidade e um movimento regional de ocupações das escolas de ensino médio, mas de forma nenhuma um movimento isolado ou restrito. Ao contrário, o movimento se deu de forma consciente em relação ao cenário nacional e completamente articulado com outros movimentos estudantis e sociais no estado de Minas Gerais. No dia 18 de outubro de 2016, a escola foi ocupada por volta das $6 \mathrm{~h}$ da manhã.

(C) ETD- Educação Temática Digital Campinas, SP $\quad$ v.19 $\quad$ n.1 $\quad$ p. 141-164 jan./mar. 2017 
Os estudantes haviam estudado o prédio e montado estratégias para a ocupação. Com a escola já aberta para as aulas do período matutino, entraram normalmente e trancaram-se com seus próprios cadeados para dentro da escola. Colaram cartazes na frente da escola e com um megafone informaram sobre os motivos da ocupação. Resistiram bravamente naquele primeiro dia às ameaças da Polícia Militar que, inclusive, deu entrevista, estarrecida sobre o ocorrido, enquanto alguns pais de alunos gritavam do lado de fora do portão, exigindo a entrada no prédio.

Se é verdade que as ocupações contaram com a agressividade de diversos pais, também não podemos ocultar o apoio que tantos outros deram à militância dos filhos. Em todos os dias de ocupação era possível ver mães na escola, abraçando suas filhas e filhos, auxiliando com as tarefas e enfrentando as ameaças reais do poder judiciário. Sobre esse aspecto, também é fundamental dizer que o campo foi quase que exclusivamente ocupado por mulheres em defesa da educação de seus filhos.

É perceptível que, com o passar dos dias nas ocupações, os estudantes apropriam-se cada vez mais do espaço escolar. Esse fato se dá concomitantemente à necessidade de articulação e resistência que sentem, à pressão que lhes é feita por movimentos e órgãos externos à escola, bem como os esforços exigidos para gerir a ocupação, conduzindo as tarefas de organização e as atividades políticas e formativas.

É necessário citar que, durante as aulas convencionais, os fatores citados acima raramente são percebidos. Os adolescentes não reconhecem a escola como pertencendo a eles, não ocupam o espaço e, portanto, não demonstram capacidade de gestão e articulação com outros grupos, o que provavelmente reflete o caráter hierárquico e opressor do meio escolar tradicional.

Durante as ocupações, os estudantes participam, planejam e organizam aulas, com colaboração ou não de outros agentes, como militantes e professores. Tais aulas têm outros significados aos estudantes. Durante uma dessas aulas, um professor de Psicologia citou as ocupações dos secundaristas como uma nova forma de militância social; relatou que locais tradicionalmente ocupados são os que não possuem papel social, como latifúndios improdutivos ou casarões abandonados; e que, possuindo a escola um caráter social bem definido, teoricamente como o lugar para aquisição de saber, as ocupações precisam ser pensadas também como um possível sintoma de que essa função social não está sendo cumprida. Portanto, o caráter político de luta pela educação em sentido amplo alia-se a uma demonstração de insatisfação em relação ao modelo escolar tradicional.

(C) ETD- Educação Temática Digital Campinas, SP $\quad$ v.19 $\quad$ n.1 $\quad$ p. 141-164 jan./mar. 2017 
Tal insatisfação pode ser percebida na construção das aulas e atividades de forma completamente diferente do que é proposto na escola convencional. Quando gerida pelos estudantes, as atividades passam a ter sentido no contexto em que estão vivendo e ligação entre si. Além das aulas de disciplinas específicas para o ENEM (Exame Nacional de Ensino Médio), como História ou Literatura, discutem o próprio sistema educacional, debatendo modelos alternativos, como o Projeto Âncora. Constroem mandalas e zines poéticos, têm aulas de yôga e sobre negritude com o próprio movimento negro, cumprindo, inclusive, o que a escola apresenta imensa dificuldade em fazer, a Lei no 10.639 de 9 de janeiro de 2003 (sobre o ensino de cultura e história afro-brasileira) e os parâmetros de educação integral. Também se atualizam sobre o cenário político.

A prática da autogestão tem se dado de modo muito eficiente. Na Escola I, por exemplo, toda noite eram determinadas cinco equipes, de segurança, comunicação, limpeza, cozinha e organização. Estudantes responsáveis pela cozinha acordavam às $5 \mathrm{~h} 30$, para muitos deles algo impensável cotidianamente. A segurança revezava-se em rondas e vigilância nos portões, e a organização era tanta que as equipes que trocariam o turno no meio da noite dormiam em quartos separados para não acordar os demais. Durante uma chuva muito forte, a equipe de segurança ficou debaixo do toldo central da escola vigiando a entrada contra ataques por mais de duas horas durante a madrugada, demonstrando o intenso sentido de responsabilidade dos estudantes. Fato curioso foi um vídeo que foi postado pela própria equipe de comunicação, posteriormente apropriado por um movimento contra a ocupação que procurou viralizá-lo nas redes sociais. No vídeo, adolescentes aparecem lavando os banheiros e fazendo a comida com alegria, dançando e cantando. Os grupos que se levantavam contra a ocupação acusaram-nos de "anarquistas" e bagunceiros. Desconsiderando o caráter de autogestão que a palavra anarquia pode abrigar, buscaram desmerecer o movimento por conta da alegria dos estudantes realizando tarefas necessárias, mas as quais os seus pais e educadores têm dificuldades de convencê-los a realizar no cotidiano. A leveza do momento demonstrado no vídeo pode simbolizar que há sentido no cuidado com a escola. Acordar cedo para lavar o banheiro ou preparar o café são tarefas realizadas e organizadas pelos próprios adolescentes, porque limpar e cuidar daquele ambiente faz sentido no processo de apropriação do espaço da escola.

Durante as assembleias e aulões, é comum estudantes contrários à ocupação irem até a escola para debater a motivação do movimento. Não raro, os argumentos contra ocupação se baseiam em questões pontuais, as notas do último bimestre, o estudo para o ENEM e o próprio ENEM. Quando discutida em âmbito mais amplo durante os aulões, a Educação é apresentada, pelos que ocuparam a escola e seus apoiadores, como tendo um valor muito mais largo e longevo do que os eventos relacionados ao calendário do final deste ano, principalmente se forem considerados os efeitos da PEC55 e da MP746.

(C) ETD-Educação Temática Digital Campinas, SP $\quad$ v.19 $\quad$ n.1 $\quad$ p.141-164 jan./mar. 2017 
Diversas questões a respeito da MP746 e PEC55 são tratadas nos aulões: a contradição entre uma proposta que congela os investimentos em educação e saúde e uma reforma do ensino médio que prevê o ensino integral; a instauração de uma reforma do ensino médio sem diálogo algum com as categorias interessadas, estudantes e professores; a possibilidade da supressão de disciplinas de grande impacto na formação política, como Sociologia e Filosofia, ou importantes para a formação integral do sujeito, como Artes e Educação Física; a possibilidade do retorno de uma escola dual no Ensino Médio, dividida entre escolas voltadas à preparação à educação superior e escolas destinadas ao ensino técnico; a confusão entre educação integral e tempo integral, entre outras. Essas questões são constantemente debatidas durante as ocupações, inclusive com a presença de especialistas de diversas áreas, como pedagogos, professores, advogados e artistas. Dessa forma, a clareza sobre as motivações das ocupações é constantemente exposta e debatida nos ambientes escolares e também nas manifestações realizadas durante esse período, como a passeata realizada pelos estudantes do campus da universidade federal no município A e o Ato Unificado Contra a PEC e a MP, que resultou na ocupação da Superintendência Regional de Ensino no município A.

Poucos dias após a ocupação da Escola I, a Escola Estadual II também foi ocupada. Ocupação bem mais fechada à participação da comunidade, mas com resistência e organização firmes. Aos poucos, outras escolas e universidades foram sendo ocupadas, as Escolas Estaduais III, IV, V, o Instituto Federal e o campus da Universidade Estadual. Por fim, o Colégio Municipal I, maior escola do município A, que conta com mais de 3.000 estudantes, foi ocupado. Essa ocupação sofreu profunda interferência da gestão municipal e do governo estadual, até então favoráveis ao movimento, que retiraram o apoio às ocupações e enviaram representantes para "fazer todo o possível para que as aulas voltassem". As aulas efetivamente voltaram, mantendose a ocupação apenas formalmente. Ficou o sentimento de que uma escola ocupada com aulas normais passa a não possuir mais o caráter de protesto que se esperava.

Diversos atores do cenário das instituições políticas formais também se fizeram presentes. Não raro, políticos de carreira apareceram nas escolas ocupadas e buscaram apoiar o movimento, no entanto, quando a ocupação chegou aos seus níveis de governo, imediatamente esse apoio passou a ser a articulação para a volta às aulas. Contudo, não é verdade que essas intervenções passaram despercebidas pelos estudantes. Em diversas ocasiões, esses políticos foram impedidos de entrar. Os estudantes recebiam os apoios que lhes eram enviados, mas na maioria das vezes não queriam ser associados à política partidária.

Atitude semelhante tiveram os estudantes em relação à intervenção da direção escolar nas ocupações. Havia escolas, como a Escola II, em que o primeiro item do cartaz de organização da ocupação referia-se às restrições à presença do diretor no prédio escolar. Na Escola I, em contrapartida, a direção possuía maior entrada na escola e tinha acesso e influência no Grêmio. No entanto, a postura do Grêmio passou a ser mais autônoma e as ocupações unificaram-se,

\section{(C) ETD-Educação Temática Digital Campinas, SP $\quad$ v.19 $\quad$ n.1 $\quad$ p. 141-164 jan./mar. 2017}


com reuniões conjuntas. Percebe-se que os estudantes passaram a "filtrar" as influências, quando sentiam que estas se chocavam com os objetivos das ocupações. Ainda na Escola I, houve sua abertura completa para as aulas, com acordo em ata, em decisão que na prática foi muito influenciado pelo diretor. Mas o acordo foi revogado quando os estudantes descobriram que o poder judiciário havia sido acionado por pais e um professor que discordava das ocupações, desrespeitando o que tinha sido definido: eles recuaram e fecharam novamente a escola, restringindo a entrada das pessoas, inclusive funcionários e direção.

Não podemos deixar de considerar a emergência de um movimento novo no cenário brasileiro, em resposta a um estado crescentemente de exceção. A direção escolar de uma das escolas foi ameaçada de ser afastada, provavelmente em uma tentativa de pressionar e criminalizar abertamente os movimentos estudantis. Por outro lado, uma nova categoria de militantes surge neste cenário opressor, os secundaristas. Esse termo não era mais utilizado após a alteração do nome do "Segundo Grau" para "ensino médio", mas ressurge como uma forma de empoderamento dos adolescentes. Os "secunda", como são chamados pelos estudantes universitários, demonstram capacidade de organização e mobilização, diante do cenário de opressão e da insatisfação pela permanência de anos em uma escola que, na prática, não dialoga com seu contexto e com suas vidas. Mais do que isto, demonstram autonomia, capacidade de autogestão, organização do espaço, articulação política e protagonismo estudantil, antes só vistos nos documentos e legislações sobre a infância e adolescência, mas muito pouco experimentados na prática, provavelmente porque, pela primeira vez, as experiências estão sendo propostas por eles próprios, os adolescentes e jovens.

\section{Ocupação do campus universitário no município $B$}

"Ocupa tudo!"; "Greve geral em toda federal!". Essas foram algumas das palavras de ordem proferidas por acadêmicos em diversos debates, mesas redondas e assembleias, entre outras atividades realizadas em um campus da universidade federal no município B no Sul de Minas Gerais. A universidade em questão, constituída por cursos de graduação e pós-graduação de diferentes áreas do conhecimento, possui uma historicidade singular e seu público tem vivenciado a constante transformação e ampliação de seus espaços estruturais e formativos. Isso fez com que a comunidade acadêmica passasse a experimentar um novo conjunto de questões que consolidaram a necessidade da composição de movimentos organizados, para dar conta das recentes configurações e demandas institucionais.

Foi preciso, portanto, fortalecer e reorganizar o movimento estudantil da universidade. Assim, tanto o Diretório Central Estudantil (DCE) quanto os coletivos e movimentos socioculturais atuantes nas mais diversas áreas (educação, sexualidade e gênero, raça, classe social, cultura etc.) têm ampliado e diversificado seus espaços de atuação, o que tem revigorado 
a sua representatividade perante a instituição e a sua comunidade. Tal condição fez com que os espaços formativos e de autogestão estudantil se desenvolvessem de forma intensa e começassem a abranger um número cada vez maior de agentes, não só da universidade, mas também da comunidade.

Com fortes críticas às posições governamentais e contrários à PEC55 e à MP746, os estudantes mobilizados, depois de vários debates, em uma assembleia histórica que contou com a participação massiva de vários coletivos e discentes independentes, deflagraram, em 21 de outubro de 2016, greve estudantil em todos os campi da universidade. Após a votação, os estudantes saíram em caminhada empunhando cartazes e proferindo palavras de ordem pela instituição para divulgar a decisão e tentar alcançar os que ainda resistiam ao estado de greve. A partir de então, a universidade em questão passa a vivenciar uma sequência de atos que, de imediato, trouxeram consequências expressivas e que alteraram a dinâmica local.

Dois episódios registram as possibilidades e os limites do diálogo intergeracional nesses episódios iniciais da ocupação.

O primeiro episódio. Em uma das assembleias que antecederam a greve, os estudantes do curso de Ciências Sociais convidaram seus professores para participar. No relato de um professor, não sabia exatamente o conteúdo da assembleia, pensava que era para discutir questões específicas do curso. Foi surpreendido por uma reunião muito bem organizada, com dois estudantes conduzindo a mesa e a distribuição de cópias da PEC55 (então, 241) para quem chegava. Realizada a leitura da PEC, um dos estudantes pediu para que "alguém" ajudasse a entender aquelas "coisas confusas". Tratava-se de um apelo para que os professores explicassem e respondessem algumas questões sobre a PEC, o que foi bem recebido pelos docentes. A seguir, um dos estudantes da mesa pediu a palavra e fez uma defesa da PEC, para constrangimento de muitos dos presentes. Não foi interrompido ao longo de sua exposição, apesar da irritação de um de seus colegas que deixou a sala reclamando em voz alta. Outra estudante, uma senhora que também é auxiliar de enfermagem, pediu a palavra e, usando tanto argumentos racionais quanto emotivos, a partir de sua história de vida, buscou tratar do quanto se conquistou nos últimos anos em direitos sociais e o quanto se arriscava perder. Enfim, os professores foram surpreendidos pela proposta de greve discente imediata, "com ocupação", que foi votada favoravelmente, quase que de modo unânime pelos estudantes.

O segundo episódio. Ao deflagrarem a greve discente, imediatamente os estudantes mobilizados procuraram interromper as aulas que estavam ocorrendo, ainda no dia 21 de outubro. Essa ação, que alguns dos estudantes posteriormente avaliaram como equivocada, gerou fortes e persistentes reclamações de docentes, inclusive de alguns que vieram a apoiar a greve geral, já que não houve aviso prévio por parte do movimento. Essas interrupções sustentaram, até o final da greve, a queixa de que o movimento estudantil feriu os direitos

(C) ETD- Educação Temática Digital Campinas, SP $\quad$ v.19 $\quad$ n.1 $\quad$ p. 141-164 jan./mar. 2017 
individuais dos que querem ministrar ou assistir aulas, ou dos que não queriam participar da greve.

Conscientes das dificuldades e diante de uma possível retaliação por parte de alguns setores da universidade, em 24 de outubro de 2016, os estudantes decidiram, em nova assembleia, dar início à ocupação da reitoria com o intuito de forçar o congelamento do calendário da instituição e de resguardar o direito à manifestação e à paralisação das atividades acadêmicas. Era preciso ousar na organização da atividade e, naquele momento, a autogestão estudantil deu uma grande aula de coordenação e de ressignificação dos espaços públicos. Fecharam, com piquetes de cadeiras e mesas, as entradas principais dos prédios e suas respectivas salas. Ao mesmo tempo, alguns estudantes tentavam dialogar com os servidores presentes para que eles deixassem seus setores de trabalho, pois o prédio estaria, a partir de então, sob o controle dos estudantes. Houve alguns conflitos pontuais e um pequeno número de técnicos foram contrários à intervenção, mas tal desavença não desmobilizou ou prejudicou a ação, pelo contrário, fortaleceu e deu maior entusiasmo às pessoas envolvidas.

No mesmo dia, houve a organização e a distribuição de tarefas. Algumas comissões foram montadas (segurança, alimentação, comunicação, limpeza etc.) com o intuito de manter a sistematização da ocupação. Espaços de descanso, de estudo, de lazer e sociabilidade, assim como a divisão de horários específicos, foram determinados coletivamente em assembleias. Tudo de forma paritária e com uma expressiva autonomia entre os grupos. Mesmo com a grande circulação de pessoas, a organização foi engenhosa e fluiu de forma coesa. A prática, a ação, a experiência e o afeto revelaram-se como uma forma de interação entre os estudantes. Com o advento de uma pauta única, ou seja, a luta contra a PEC55 e o congelamento do calendário, houve a estruturação de um sentimento de coletividade que transpassou barreiras ideológicas, simbólicas e materiais. Grupos e coletivos, que em outros momentos sofriam com as contradições e divergências próprias de suas inter-relações, passaram a ocupar um espaço único. Estudantes ligados a diferentes grupos e/ou que nunca participaram ativamente do movimento estudantil começaram a integrar a mobilização e a preencher posições de destaque. Mesmo com algumas divergências pontuais, a aprendizagem passou a se figurar de forma coletiva e dialógica. Todos passaram a aprender e a ensinar. A cada atividade, a cada discussão, a cada assembleia, foi possível perceber o envolvimento de todos os estudantes participantes. O próprio espaço de ocupação passou a ter a cara do movimento. Cartazes, colchões, barracas, instrumentos musicais, a organização da cozinha e dos espaços de alimentação, tudo isso adquiriu um novo significado e revelou a horizontalidade das relações entre os discentes - característica ressaltada por muitas pessoas que circularam pelos espaços ocupados.

No dia 27 de outubro de 2016, após uma sessão conturbada e que aconteceu sobre grande pressão, os professores da universidade, em um movimento de vanguarda, declararam greve em uma das maiores assembleias docentes já realizadas na história da instituição. Vale

(C) ETD- Educação Temática Digital Campinas, SP v.19 $\quad$ n.1 $\quad$ p. 141-164 jan./mar. 2017 
ressaltar que os técnicos da instituição já haviam declarado greve, contudo, é somente com o fortalecimento do processo de ocupação estudantil que as três categorias (estudantil, docente e técnico-administrativa) conseguiram se unir em uma pauta única e formar um comando geral de greve horizontal, democrático e com a participação ativa de todos os que desejassem.

Em 31 de outubro de 2016, em uma ação conjunta entre docentes e discentes, o calendário é congelado. Docentes e discentes com direito a voto ou participação na reunião do colegiado da Pró-reitoria de graduação articulam interessante discurso comum, acerca da importância de participar da mobilização nacional contra a PEC55, a respeito dos malefícios dessa PEC, sobre a necessidade de proteger os discentes da ameaça de desocupação violenta e de proteger os próprios servidores do corte do ponto, permitida poucos dias antes por uma polêmica decisão do Supremo Tribunal Federal. A seguir, a reitoria afirma o compromisso de que nenhum estudante sofreria qualquer tipo de retaliação por conta das mobilizações.

Entretanto, surge mais uma complicação. Nos dias 5 e 6 de novembro de 2016, a instituição receberia estudantes secundaristas de toda a região, dado que seria realizado o ENEM. O Ministério da Educação (MEC), por meio do Instituto Nacional de Estudos e Pesquisas Educacionais Anísio Teixeira (Inep), queria uma resposta imediata do movimento estudantil. A posição do MEC era única, ou seja, com a ocupação, o ENEM seria cancelado na instituição. Após debate e votação, os estudantes, conscientes das possíveis consequências que tal medida teria, decidiram desocupar a reitoria e ocuparam o prédio de Extensão Universitária, que está localizado fora dos espaços do campus central. Duas soluções em uma única ação. Assim, tanto os estudantes secundaristas que fariam a prova não seriam afetados, como o movimento de ocupação seguiria em mobilização.

Os dias que se seguiram foram de reorganização do movimento e das comissões internas de ocupação. Era preciso abrir e fortalecer o diálogo com a população local, bem como criar ações de interação e de sociabilidade. Como forma de conscientizar a sociedade sobre sua luta, os estudantes dividiram-se em blocos, que ficaram encarregados de distribuir materiais e panfletos informativos em todo o município. Além disso, o movimento concentrou-se na organização de atividades culturais e formativas, com grande apoio dos docentes mobilizados, como passeatas, aulões públicos, mesas redondas, apresentações artísticas, entre outros, o que qualificou a ressignificação dos espaços da instituição e possibilitou o estreitamento das relações com a comunidade local.

Todo esse contexto revela o potencial vanguardista dos estudantes universitários sul mineiros. Ao nos afastarmos metodologicamente, é possível visualizar que as ações desses jovens têm alterado e ressignificado a compreensão da comunidade acadêmica sobre o papel da universidade e de seus espaços formativos. As mobilizações estudantis têm sido um espaço de debate caracterizado pela crescente adesão e participação coletiva dos envolvidos. A presença

(C) ETD- Educação Temática Digital Campinas, SP v.19 $\quad$ n.1 $\quad$ p.141-164 jan./mar. 2017 
de pessoas contrárias e favoráveis às pautas e deliberações do movimento têm diversificado o diálogo e estabelecido uma condição de horizontalidade difícil de alcançar nos âmbitos burocráticos e formais da instituição. Ademais, tais atividades têm alcançado um grau de organização e de engajamento maior do que muitas das ações coordenadas por outras categorias da universidade, condição que tem aumentado o reconhecimento dos estudantes mesmo perante setores mais conservadores.

Diversas ações favoreceram, fortaleceram e consolidaram os estudantes como agentes sociais que podem e devem contribuir para a afirmação e a ampliação dos direitos a uma educação pública universal e de qualidade, tais como: debates, assembleias, composição de comissões, elaboração de atividades diárias de organização e manutenção dos espaços ocupados, bem como a abertura de diálogo com a população externa e a aproximação e contribuição para com os estudantes da educação básica, entre outros.

Todavia, vale ressaltar que o movimento estudantil teve que enfrentar uma série de contrariedades e oposições. Alguns sujeitos mais conservadores da comunidade acadêmica (discentes, docentes, técnicos e administração) lançaram mão de artifícios com o intuito de deslegitimar os posicionamentos e ações do movimento. Ainda assim, as mobilizações estudantis alcançaram diversos de seus objetivos e tiveram a maioria de suas demandas debatidas em espaços importantes da instituição, incluindo o Conselho Universitário, órgão máximo da estrutura organizacional da universidade.

O movimento de greve e ocupação estudantil revelou-se como um espaço de formação por excelência. Ali, a universidade, em todas as suas representações, pôde perceber a posição progressista dos estudantes sobre questões que muitas vezes são silenciadas no âmbito educativo institucional. Estudantes tornaram-se formadores, agentes auto-organizados e personagens principais de um processo de enfrentamento que atingiu todo o país.

Enquanto escrevíamos este artigo, o movimento no campus universitário do município $\mathrm{B}$ prosseguia. Enfrentava as tensões e contradições que aparecem ou se criam em um movimento de longa duração que reúne sujeitos com diferentes posições (estudantes de graduação e pósgraduação, docentes e técnicos) e de diferentes categorias etárias (jovens e adultos). $\mathrm{Na}$ observação das reuniões do comando geral de greve, notaram-se algumas dessas tensões. Os estudantes realizavam suas próprias assembleias diárias, enviando um ou outro representante para as reuniões do comando, indicando que davam mais importância às suas próprias reuniões, por vezes encaradas como soberanas ou autoinstituintes, sem precisar da legitimação do comando geral. Por sua vez, as reuniões do comando eram compostas principalmente por docentes e adultos. Em um momento de tensão, devido ao impacto negativo na mídia local de uma ação intempestiva de um coletivo estudantil (que estimulou a ocupação de uma escola pública no município B), alguns discursos revelaram possíveis fissuras na coalizão que construiu 
esta greve geral. Entre os discursos, primeiro, a valorização da experiência, seja pela evocação da participação em movimentos grevistas de outrora, seja pela denúncia do que seria a onipresente tática de "aparelhamento" do movimento estudantil por partidos de esquerda. Segundo, certa desautorização das táticas do movimento estudantil (focando o episódio das interrupções de aulas, sem aviso prévio de greve discente) e até mesmo a minimização do vanguardismo de sua ação na greve geral.

Por outro lado, antes e depois dessas tensões, estudantes, docentes e técnicos organizaram "aulões", conversações e mesas-redondas sobre diversos temas, tais como, PEC55, MP746, reforma política, história do movimento estudantil, diálogo entre gerações, teoria crítica, literatura africana, semiótica da arte, primeiros socorros etc. Realizaram cine debates e oficinas sobre diferentes temas, como defesa pessoal, parkour e marcadores de página, entre outros. Buscaram o diálogo com a sociedade civil, por meio de panfletagem, entrevistas na mídia, conversas com as comunidades católicas (sob o estímulo da CNBB [Confederação Nacional dos Bispos do Brasil], que também condenou a PEC55) e atividades recreativas para as crianças. Organizaram, enfim, uma das maiores manifestações da história do município $B$, no dia 11 de novembro de 2016, dia de mobilização nacional contra a PEC55. Nesse sentido, a dinâmica do movimento social, no seu labor criativo, apesar das tensões citadas acima, foi sobretudo um laboratório do diálogo entre gerações.

\section{CONSIDERAÇÕES FINAIS}

Segundo Jaspers (2016), são de grande importância, para os movimentos sociais, os espaços livres, tais como centros comunitários, igrejas, bares e escolas, para que os manifestantes potenciais criem, debatam e formulem seus desconfortos e suas demandas sem repressão imediata. O Brasil tem visto a diminuição desses espaços de livre abertura ao debate e à construção da opinião, e as escolas da educação básica pouco fizeram esse papel de acolhimento dos movimentos sociais outrora. É surpreendente que tenham sido justamente elas os canais do protesto contra as medidas mais polêmicas do governo Temer, porque não se trata apenas de usufruir um espaço livre para a politização dos sujeitos, mas também de criar esse espaço e defendê-lo.

Isso não nos autoriza, entretanto, a concluir que o movimento das ocupações teve origem "espontânea". Realmente, foi fundamental o momento em que muitos estudantes independentes ou até então desmobilizados acorreram massivamente ao apelo da ocupação. Mas o movimento só foi possível pelo trabalho cotidiano dos coletivos estudantis. $\mathrm{Na}$ universidade federal, a greve discente e a ocupação foram precedidas por inúmeras ações fomentadas pelos coletivos estudantis, ligados a juventudes de partidos ou a movimentos sociais mais amplos, que detêm o DCE ou o disputam. Também nas escolas de ensino médio, houve um 
relevante trabalho de politização que precedeu o movimento social, como no caso da rede de coletivos feministas, com apoio da UBES, no município A, e a atuação do grêmio estudantil da escola I.

O encontro entre o trabalho de formação política pelos coletivos juvenis e a autogestão, entretanto, foi possível graças à ocupação das unidades estudantis, repetindo uma fórmula que apareceu de maneira impactante pela primeira vez em 1968. Agora, no Brasil em 2016, a autogestão manifesta-se na reorganização do espaço disciplinar das escolas de ensino médio, algo patente na escola I do município B, cujo prédio abrigara um sanatório, ou seja, com estrutura originalmente destinada a isolar os sujeitos em relação ao exterior, agora usada como forma de proteger o movimento e criar um espaço livre e autônomo dos estudantes.

Houve um grande esforço para organizar os espaços e as atividades, para ocupar o tempo, manter o movimento forte e resistir às ameaças de desocupação. Formaram-se equipes e/ou comissões para gerir as atividades, proteger o espaço e manter o diálogo com o poder público e a sociedade. As assembleias soberanas tenderam a criar as normas que regiam a ocupação, fazendo da multidão estudantil um poder instituinte (NEGRI; HARDT, 2004), mesmo que provisório e até efêmero. Construiu-se um sentimento coletivo, forte especialmente no auge das ocupações, uma solidariedade que dissipou momentaneamente divergências ideológicas e disputas de poder entre os coletivos estudantis.

A autogestão das ocupações permitiu o auto-aprendizado - ou o co-aprendizado entre militantes com mais experiência ou pelo diálogo com adultos apoiadores - de habilidades não cultivadas - ou não notadas - nas atividades educacionais convencionais. Habilidades construídas ou exercitadas na organização dos "aulões", debates, seminários, oficinas, atividades culturais, assembleias, manifestações, entre outros. Também, exercidas na gestão e execução de tarefas como limpeza, segurança, cozinha etc., por vezes realizadas com inesperada alegria.

A formação política pelo movimento manifestou-se mesmo antes deste entrar em ebulição, como no longo processo de debates sobre a PEC55, na universidade federal, em assembleias discentes ou gerais. Manifestou-se, ainda, na repentina decisão de greve discente com ocupação, na mesma universidade. Continuou nas assembleias dos estudantes universitários, as quais adotaram uma metodologia que valorizava a participação e a horizontalidade das decisões, sem que isso significasse a perda da noção de estratégia e da necessidade de eleger uma pauta clara, a saber, pressionar o congelamento do calendário e participar de um movimento nacional contra a PEC55. A noção de estratégia também esteve presente na decisão de desocupar a reitoria após a conquista da demanda e para evitar o cancelamento do ENEM no campus, tentando não perder a opinião favorável da população local.

(C) ETD- Educação Temática Digital Campinas, SP $\quad$ v.19 $\quad$ n.1 $\quad$ p. 141-164 jan./mar. 2017 
As assembleias estudantis tenderam a ter caráter soberano e autoinstituinte, mesmo nos casos em que a direção deu apoio velado, ou naqueles que foram feitos acordos com autoridades. O caráter soberano das assembleias estudantis também se manteve na universidade, apesar de ter sido formado um comando de greve unificado. Na universidade, estudantes, docentes e técnicos mobilizados realizaram uma série de ações em conjunto, em especial para levar a mensagem do movimento à população local, como panfletagens, colagem de cartazes, entrevistas na mídia local, eventos e manifestações. Entretanto, graças ao caráter vanguardista do movimento estudantil e à autogestão da ocupação, os estudantes pareceram assumir uma posição de poder instituinte dentro do movimento, concentrando esforços na ocupação, nas suas assembleias e atividades.

Na universidade, não foram poucos os professores que adotaram o discurso de que, com seu papel de vanguarda, os estudantes é que estavam ensinando os educadores e politizando-os Essa motivação pesou a favor da decisão pela greve docente, ainda que, na verdade, tenha se misturado a certo paternalismo, dada a necessidade de proteger os estudantes mobilizados de uma possível retaliação ou repressão - considerando o exemplo de casos recentes de desocupações violentas de escolas.

O movimento das ocupações tem forçado as gerações ao diálogo. Ao menos, a se defrontar e confrontar. Mesmo quando o diálogo é negado, ele não deixa de ser imperioso. 0 exemplo citado acima, do apoio dos docentes aos estudantes motivado por um misto de coaprendizado e paternalismo, indica que há, no mínimo, ambiguidades. Os exemplos a seguir tratam das dificuldades desse diálogo necessário: a defesa da tradição por diversos adultos e autoridades, no caso da ocupação de antigo colégio estadual no município $A$; a intervenção da gestão municipal e estadual no município $A$, forçando a manutenção das aulas no colégio municipal, mesmo com a ocupação; políticos que buscavam se promover, posando ao lado do movimento, mas mudando de posição quando as ocupações atingiram governos comandados por seu partido; assembleia de estudantes que cria, como norma "número 1", restrições à presença do diretor da escola, visto com desconfiança; greve discente que declara imediatamente a interrupção das aulas, sem aviso anterior, gerando reiterada e injustificada classificação do movimento como "truculento" e "agressivo", mesmo diante dos esforços dos estudantes para criar canais de diálogo com servidores insatisfeitos; caráter soberano das assembleias discentes acarreta uma participação pequena dos estudantes no comando de greve geral da universidade, enquanto este, formado principalmente por servidores adultos, às vezes aproxima-se do discurso que recria o "poder adulto" ou a superioridade da "experiência".

Em contrapartida, os exemplos do diálogo geracional bem-sucedido são notáveis, fartos, principalmente no auge das ocupações, em que a solidariedade é o sentimento mais forte: apoio das mães, em especial, aos estudantes que ocuparam as escolas do município A; boa relação da

\section{(C) ETD-Educação Temática Digital Campinas, SP $\quad$ v.19 $\quad$ n.1 $\quad$ p. 141-164 jan./mar. 2017}


direção da escola I com o movimento, pelo menos antes de um professor e um pai terem entrado com pedido de reintegração de posse na justiça; pedido de estudantes em assembleias para que seus professores ajudassem-nos a entender a PEC55, ainda que esses mesmos professores se vissem surpreendidos pela votação da greve discente imediata com ocupação; construção de um comando unificado na universidade, com espaço aberto para quem quisesse participar, e sem hierarquias formais entre os participantes; a busca de estudantes mobilizados pelo diálogo na universidade com professores e técnicos que queriam ter acesso a espaços de trabalho, como laboratórios e escritórios; greve docente e esforço comum de congelamento do calendário na universidade em apoio à greve estudantil e também para evitar retaliações.

Enfim, ao novamente trazermos Jaspers (2016), agora acerca das consequências biográficas da participação em um movimento social, no mínimo, temos, com as ocupações, a formação de uma importante parcela de sujeitos com grande sensibilidade para as questões políticas e para uma visão mais progressista acerca da sociedade. Ainda que o movimento não tenha alcançado suas metas, detendo a PEC55 ou revendo a MP746, e mesmo que não evite o crescente caráter de exceção do atual Estado brasileiro, esses sujeitos, hoje adolescentes ou jovens, continuarão tendo grande importância como fomentadores e militantes dos próximos movimentos pelas garantias democráticas e pela reconquista de direitos sociais por ora ameaçados. São adolescentes e jovens formados menos teórica ou abstratamente a respeito das bases do regime político, menos na simulação de procedimentos democráticos e decisórios, e mais na vivência concreta de um movimento social, participando de assembleias, comissões, manifestações e até mesmo sofrendo a repressão ou a sua ameaça.

\section{REFERÊNCIAS}

ANTUNES, André. Ocupar, lutar, resistir. Revista Poli - Saúde, Educação, Trabalho. Rio de Janeiro, Ano VIII, n. 44, mar./abr. 2016, p. 4-10. Disponível em:

http://www.epsjv.fiocruz.br/noticias/reportagem/ocupar-lutar-resistir. Acesso em: 10 set. 2016.

ARANTES, Paulo. Depois de junho a paz será total. In: ARANTES, Paulo. O novo tempo do mundo: e outros ensaios sobre a era da emergência. São Paulo: Boitempo, 2014, cap. 5, p. 353-460. 490 p. ISBN 978-85-7559-367-7.

ARROIO, Miguel. Repensar o Ensino Médio: por que? In: DAYRELL, Juarez; CARRANO, Paulo; MAIA, Carla. (Orgs.). Juventude e ensino médio: sujeitos e currículos em diálogo. Belo Horizonte: UFMG, 2014, p. 53-74. 339 p. ISBN 978-85-423-0070-3

BOBBIO, Norberto. Direita e esquerda. Razões e significados de uma distinção política. $2^{\mathrm{a}}$ ed. São Paulo: Ed. Unesp, 2001.

CASTRO, Elisa G. Entre ficar e sair. Uma etnografia da construção social da categoria jovem rural. Rio de Janeiro: Contracapa, 2013. 432 p. ISBN 978-8577401-34-5

(C) ETD-Educação Temática Digital Campinas, SP v.19 $\quad$ n.1 $\quad$ p.141-164 jan./mar. 2017 
CASTRO, Lúcia Rabello de. Juventude e socialização política: atualizando o debate. Psicologia: Teoria e Pesquisas. v. 25, n. 4, 2009, p. 479-487. Disponível em:

http://www.scielo.br/pdf/ptp/v25n4/a03v25n4.pdf. Acesso em: 10 mar. 2016.

CASTRO, Lúcia Rabello de; MATTOS, Amans Rocha. O que é que a política tem a ver com a transformação de si? Considerações sobre a ação política a partir da juventude. Análise Social. v. XLIV (193), 2009, p. 793-823. Disponível em:

http://analisesocial.ics.ul.pt/documentos/1260461328M1jFM7cp0EI76KE1.pdf. Acesso em: 05 abr. 2016.

FOLHA DE S. PAULO. Brasil tem 1.154 unidades de ensino ocupadas por alunos, diz entidade.

26/out./2016. Disponível em: http://www1.folha.uol.com.br/educacao/2016/10/1826548-brasil-tem1154-unidades-de-ensino-ocupadas-por-alunos-diz-entidade.shtml. Acesso em: 4 /nov./2016.

FOLLIS, Massimo. Autogestão. In: Norberto BOBBIO et al. (orgs.). Dicionário de política. 5.ed., vol. 1, Brasília: Ed. Da UnB, Imprensa Oficial, p. 74-81, 2000. 674 p. ISBN 85-230-0309-6.

FOUCAULT, Michel. Vigiar e punir: nascimento da prisão. 29.ed. Petrópolis: Vozes, 2009. 288 p. ISBN 85-326-0508-7.

GENTILI, Pablo (Ed.). Golpe em Brasil: genealogía de uma farsa. Buenos Aires : CLACSO; Fundación Octubre; UMET, Universidad Metropolitana para la Educación y el Trabajo, 2016a.

GENTILI, Pablo. Brasil: estado de excepción. In: GENTILI, Pablo (ed.). Golpe em Brasil: genealogía de uma farsa. Buenos Aires : CLACSO; Fundación Octubre; UMET, Universidad Metropolitana para la Educación y el Trabajo, 2016a.p. 27-34, 2016b.

GROPPO, Luís Antonio. Autogestão, universidade e movimento estudantil. Campinas: Autores Associados, 2006.

INTERVOZES. A cobertura midiática das escolas ocupadas: silêncio e criminalização. 2/nov./2016. Disponível em: http://www.cartacapital.com.br/blogs/intervozes/a-cobertura-das-escolas-ocupadassilencio-e-criminalizacao. Acesso em: 4 nov. 2016.

JASPERS, James J. Protesto: uma introdução aos movimentos sociais. Rio de Janeiro: Zahar, 2016. 230 p. ISBN 978-85-378- 556-4.

MARICATO, Ermínio et al. Cidades rebeldes: Passe Livre e as manifestações que tomaram as ruas do Brasil. São Paulo: Boitempo: Carta Maior, 2013. 112 p. ISBN 978-85-7559-34-1.

MOLL, Jaqueline (org.). Os tempos da vida nos tempos da escola: construindo possibilidades. 2a ed. Porto Alegre: Penso, 2013. 261 p. ISBN 978-85-65848-58-9.

MOSÉ,Viviane. A escola e os seus desafios contemporâneos. Rio de Janeiro: Civilização Brasileira, 2013. 336 p. ISBN 978-85-20001-208-6.

(C) ETD-Educação Temática Digital Campinas, SP $\quad$ v.19 $\quad$ n.1 $\quad$ p.141-164 jan./mar. 2017 
MÜXEL, Anne. Jovens dos anos noventa: à procura de uma política sem "rótulos". Revista Brasileira de Educação. maio/ago. de 1997, n. 5-6, p. 151-166.

NATANSON, Jacques-J. Les éducaeurs à l'épreuve. Esprit. n. 374, Paris, p. 313-328, out. 1968.

NEGRI, Antonio; HARDT, Michael. 0 trabalho de Dioniso. Para a crítica ao Estado pós-moderno. Juiz de Fora: Editora UFJF, Pazulin, 2004. 232 p. ISBN 85-85252-86-3.

OLIVEIRA, Marta Kohl de. Ciclos de vida: algumas questões sobre a psicologia do adulto. Educação \& Pesquisa. São Paulo, v. 30, n. 2, p. 211-229, maio/ago. 2004. Disponível em:

http://www.revistas.usp.br/ep/article/view/27931/29703. Acesso em: 24 jun. 2016.

OPPO, Anna. Socialização política. In: BOBBIO, N.; MATTEUCCI, N.; PASQUINO, G. (org.). Dicionário de política. 11a ed. Brasília: Editora da UnB, 1998, p. 1202-1206. 1330 p. ISBN 85-230-0308-8.

PARK, Margareth; GROPPO, Luís Antonio (orgs.). Holambra: Setembro, 2009.

PERALVA, Angelina. O jovem como modelo cultural. Revista Brasileira de Educação. maio/ago. de 1997, n. 5-6, p. 15-24.

PIOLLI, Evaldo; PEREIRA, Luciano; MESKO, Andressa S. R. A proposta de reorganização escolar do governo paulista e o movimento estudantil secundarista. Crítica Educativa (Sorocaba/SP), vol. 2, n. 1, p. 21-35, jan./jun. 2016. Disponível em:

http://www.criticaeducativa.ufscar.br/index.php/criticaeducativa/article/view/71. Acesso em: 23 set. 2016.

RANCIÈRE, Jacques. O ódio à democracia. São Paulo: Boitempo, 2014. 128 p. ISBN 978-85-75594001.

SANTOS, Boaventura de Sousa; RODRÍGUEZ, César. Introdução: para ampliar o cânone da produção. In: SANTOS, Boaventura de Sousa (org.). Produzir para viver: os caminhos da produção não capitalista. Rio de Janeiro: Civilização Brasileira, p. 23-77, 2002. 518 p. ISBN 978-85-20006054.

SILVA, Conceição Firmina S.; CASTRO, Lúcia Rabello de. Para além das fronteiras convencionais do ativismo político: a inserção de jovens em "coletivos fluidos". In: BEZERRA, Helena D.; OLIVEIRA, Sandra Maria de. Juventude no século XXI: dilemas e perspectivas. Goiânia: Cânone Editorial, 2013, p. 14-44. 216 p. ISBN 978-85-80580174.

SOUSA, Janice Tirelli P. de. A experiência contemporânea da política entre jovens do Sul do Brasil. Relatório de pesquisa. Buenos Aires: CLACSO, 2014. Disponível em: biblioteca.clacso.edu.ar/clacso/becas/20140623015303/RELATORIOJaniceTirelli.pdf. Acesso em: 10/maio/2016, Acesso em: 10 jun. 2016.

\footnotetext{
' Revisão gramatical do texto por: Ana Amélia Furtado de Oliveira
} 